\title{
In vitro comparison of the amount of salbutamol available for inhalation from different formulations used with different spacer devices
}

\author{
P.W. Barry, C. O'Callaghan
}

In vitro comparison of the amount of salbutamol available for inhalation from different formulations used with different spacer devices. P.W. Barry, C. O'Callaghan. (CERS Journals Ltd 1997.

ABSTRACT: Metered-dose inhalers (MDIs) are currently being reformulated to contain hydrofluoroalkanes (HFAs), which do not damage the Earth's ozone layer. As different formulations of inhaled drugs may behave differently when used with spacer devices, we wished to determine the amount of salbutamol available for inhalation from a conventional metered-dose inhaler (Ventolin ${ }^{\circledR}$ ) and a new HFAcontaining formulation (Airomir $\left.{ }^{\circledR}\right)$, when used with two different spacers.

A glass multistage liquid impinger was used to determine the amount of salbutamol delivered from the inhalers used with the Aerochamber ${ }^{\circledR}$ and the Nebuhaler ${ }^{\circledR}$ spacer devices. High speed video-recordings of inhaler actuation into air were made, and the speed of the aerosol and the aerosol cloud volume were measured.

More salbutamol in small particles $(<5 \mu \mathrm{m})$ was delivered from the Airomir ${ }^{\circledR}$ MDI than the Ventolin ${ }^{\circledR}$ MDI, when used with the Aerochamber ${ }^{\circledR}(40.4(95 \%$ confidence interval (95\% CI) 31.2-49.6) versus $19.5(19.0-20.0) \mu \mathrm{g})$ and the Nebuhaler ${ }^{\circledR}$ (42.1 (36.3-47.9) versus 24.6 (23.3-25.8) $\mu \mathrm{g})$. The aerosol cloud from the Airomir ${ }^{\circledR}$ MDI was slower than the Ventolin ${ }^{\circledR}$ aerosol, and $60 \mathrm{~ms}$ after actuation had travelled $186 \mathrm{~mm}$, whereas the Ventolin $®$ aerosol had travelled $320 \mathrm{~mm}$. At the same time, the Airomir ${ }^{\circledR}$ aerosol occupied a smaller volume than the Ventolin ${ }^{\circledR}$ MDI (251 (213-288) versus $\left.695(608-782) \mathrm{cm}^{3}\right)$.

The hydrofluoroalkane formulation delivers more salbutamol than the conventional formulation when used either with the Aerochamber ${ }^{\circledR}$ or Nebuhaler ${ }^{\circledR}$ spacer. This may be because less drug is deposited in the spacer from the hydrofluoroalkane formulation, which is emitted from the metered-dose inhaler at a slower speed and occupies a smaller volume than the conventional formulation. The observed difference in drug delivery may be important for patients changing formulations, and in severe asthma, where high doses of salbutamol may be administered through a spacer.

Eur Respir J 1997; 10: 1345-1348.
Dept of Child Health, University of Leicester, Leicester, UK.

Correspondence: C. O'Callaghan

Dept of Child Health

University of Leicester

Clinical Sciences Building

Leicester Royal Infirmary

PO Box 65

Leicester

LE2 7LX

UK

Keywords: Chlorofluorocarbons drug administration (inhalation) salbutamol spacer devices

Received: March 31996

Accepted after revision February 201997

P.W.B. is funded by the Astra Foundation.
The majority of metered-dose inhalers (MDIs) used for inhalational therapy contain chlorofluorocarbons (CFCs) as propellants. These compounds contribute to the depletion of the Earth's ozone layer, and are, therefore, being phased out of use [1]. Medical use of CFCs has been granted a temporary exemption from agreements banning $\mathrm{CFCs}$, and alternative propellants are being investigated. Recently, a MDI of salbutamol containing the hydrofluoroalkane, HFA $134 \mathrm{a}$, as a propellant, has been licensed for use in the UK (Airomir ${ }^{\circledR}, 3 \mathrm{M}$ Pharmaceuticals, Loughborough, UK).

Spacer devices are commonly used as aids for inhalational therapy. They allow MDIs to be used by patients, such as young children, who find it impossible to coordinate MDI actuation and inhalation. A number of studies have shown the clinical benefit of spacer use in asthma for the delivery of salbutamol by MDIs containing CFCs [2], but there are no published studies of drug output from spacer devices used with formulations containing no CFCs. We have previously shown: that there are differences in the proportion of different medications delivered from spacers [3]; that differences in spacer static charge affect drug output from spacers [4]; and that differences exist in aerosol plume geometry between different medications [5]. We postulated that MDIs containing CFC and HFA would have different aerosol characteristics and would deliver different amounts of medication from spacer devices.

We therefore used an in vitro method to determine the amount of salbutamol available for inhalation in various particle size fractions from the two MDIs used with different spacer devices, and measured the speed and volume of the aerosol cloud produced by the two MDIs

\section{Methods}

\section{Aerosol particle size}

A four stage glass multistage liquid impinger (MSLI) $[6,7]$ was used to determine the MDI output under 
different conditions. The MSLI operates by drawing an aerosol through an inlet consisting of a glass cylinder with a right-angled bend, and then through a series of stages, each containing a glass impaction plate. Aerosol is drawn through the MSLI at a flow of $60 \mathrm{~L} \cdot \mathrm{min}^{-1}$. Aerosol velocity increases in the device, and progressively smaller particles collect at each stage. A filter after the final stage collects the smallest particles. After each experiment, the inlet and stages were washed with methanol and the amount of drug collected at each stage determined by high pressure liquid chromatography using an internal standard [8].

Experiments were undertaken using a CFC-containing formulation of salbutamol (Ventolin ${ }^{\circledR}$, Allen \& Hanburys Ltd, Uxbridge, UK), and a non-CFC formulation (Airomir®); 3M Pharmaceuticals, Loughborough UK). Both formulations are marketed to deliver $100 \mu \mathrm{g}$ of salbutamol per actuation. They were assessed with the following spacers: Nebuhaler® (Astra Pharmaceuticals, Kings Langley, UK), Aerochamber ${ }^{\circledR}$ (Trudell Medical, London, Canada), and a Nebuhaler ${ }^{\circledR}$ coated with static dissipative paint (U-100; Static Safe Environments Ltd, Birmingham, UK).

New spacers were used for each experiment. The child Aerochamber ${ }^{\circledR}$ was used with the mask removed. New MDIs of each drug were obtained. The first 10 actuations from each MDI were fired to waste. Between experiments, MDIs were stored on their sides. Immediately prior to each experiment, the MDI was shaken for $30 \mathrm{~s}$ and primed by firing one actuation to waste. The MDI was then shaken for $10 \mathrm{~s}$ and actuated into the MSLI or into the spacer, which was immediately attached to the MSLI. Both MDI and spacers were connected to the MSLI via a short plastic sock. This procedure was repeated 10 times during each experiment to facilitate the drug assay.

Experiments were repeated four times, and the laboratory temperature and relative humidity were recorded for each experiment.

The size distribution of the aerosol cloud was determined from the amount of drug recovered from each stage, the MSLI having previously been calibrated with an aerosol of known particle size distribution. The cutoff diameters for the four stages were: 11.2, 7.0, 4.7 and $1.0 \mu \mathrm{m}$, respectively. From the size distribution, a log-probability plot was constructed [9], and characteristics of the aerosol determined, such as the amount of drug contained in particles less than 5 or $3 \mu \mathrm{m}$, the mass median aerodynamic diameter (MMAD, i.e. the aerodynamic size of a particle, such that half of the drug is in larger and half in smaller particles), and the geometric standard deviation (GSD), a measure of the heterogeneity of the aerosol particle size. Mean recovery of salbutamol from the two formulations via each spacer was compared using a two-tailed t-test.

\section{Aerosol plume geometry}

Metered-dose inhalers of both formulations were actuated into still air and recorded on high-speed video using the Kodak EKTAPRO HS 4540 motion analysis system (Kodak Ltd, Hemel Hempstead, UK), sampling images at 500 frames $\cdot \mathrm{s}^{-1}$, and recording them on a Video Home
System (VHS) video-tape. The video was then played back at a much slower rate, and measurements of the aerosol cloud were made with callipers on the monitor screen, starting from when the cloud could first be discerned appearing at the MDI adapter exit. The MDI adapter was measured in the horizontal and vertical plane to calibrate the monitor measurements.

Measurements were made from the MDI adapter to the leading edge of the cloud, allowing aerosol speed to be computed. Volume of the aerosol cloud was estimated by measuring the maximum vertical dimension of the cloud, the horizontal distance from the MDI adapter to the maximum vertical dimension, and the distance from there to the leading edge of the cloud. The cloud was assumed to be conical in shape from the MDI adapter to its leading edge. Summary measures were used to analyse the speed and volume of the aerosol [10]. These comprised distance travelled by the leading edge of the aerosol cloud and volume of the cloud 60 $\mathrm{ms}$ after MDI actuation, and were compared for the two drugs using a two-tailed t-test. A p-value less than 0.05 was considered statistically significant.

\section{Results}

\section{Aerosol particle size}

Although the ideal particle size for drug delivery to the lungs is not known, particles smaller than $5 \mu \mathrm{m}$ are thought to be optimal. We report on the mean amount of salbutamol delivered from the devices under test contained in particles smaller than 5 and $3 \mu \mathrm{m}$, the MMAD and the GSD (table 1).

From each $100 \mu \mathrm{g}$ actuation, $37.2 \mu \mathrm{g}$ (95\% confidence interval $(95 \% \mathrm{CI}) 35.5-38.8 \mu \mathrm{g})$ of salbutamol in particles smaller than $5 \mu \mathrm{m}$ was delivered from the Airomir® MDI without a spacer, compared with 46.3 $\mu \mathrm{g}(36.3-56.3 \mu \mathrm{g})$ from the Ventolin ${ }^{\circledR}$ MDI $(\mathrm{p}=0.13)$ (fig. 1). With the Airomir® MDI and Aerochamber® spacer, $40.4 \mu \mathrm{g}(31.2-49.6 \mu \mathrm{g})$ was delivered in particles smaller than $5 \mu \mathrm{m}$, compared with $19.5 \mu \mathrm{g}$ (18.9-20.0 $\mu \mathrm{g})$ from the Ventolin ${ }^{\circledR}$ MDI and Aerochamber ${ }^{\circledR}(\mathrm{p}=$ 0.013). Similarly, with the Nebuhaler ${ }^{\circledR}$, the Airomir ${ }^{\circledR}$ MDI delivered more drug in particles smaller than 5 $\mu \mathrm{m}, 42.1 \mu \mathrm{g}(36.3-47.9 \mu \mathrm{g})$ compared to $24.6 \mu \mathrm{g}$ $(23.3-25.8 \mu \mathrm{g})$ from the Ventolin ${ }^{\circledR}$ MDI $(\mathrm{p}=0.001)$. Delivery of salbutamol in particles smaller than $5 \mu \mathrm{m}$ from both formulations was increased by the use of the antistatic Nebuhaler ${ }^{\circledR}$, to $74.8 \mu \mathrm{g}(64.0-85.6 \mu \mathrm{g})$ from the Airomir ${ }^{\circledR}$ MDI, and to $68.5 \mu \mathrm{g}(61.2-75.7 \mu \mathrm{g})$ from the Ventolin ${ }^{\circledR}$ MDI. There was no significant difference between the formulations used with the antistatic Nebuhaler ${ }^{\circledR}(\mathrm{p}=0.38)$.

A mean of $100.4 \mu \mathrm{g}$ of salbutamol was recovered from the experimental apparatus per $100 \mu \mathrm{g}$ actuation. There was no difference in total recovery between experiments using Airomir ${ }^{\circledR}$ or Ventolin ${ }^{\circledR}$ (t-test, $\mathrm{p}=0.8$ ).

\section{High-speed video analysis (fig. 2)}

When first visualized, the leading edge of the Airomir ${ }^{\circledR}$ aerosol was travelling at $14 \mathrm{~m} \cdot \mathrm{s}^{-1}$, decelerating to $3 \mathrm{~m} \cdot \mathrm{s}^{-1}$ after $10 \mathrm{~ms}$. The initial speed of the Ventolin ${ }^{\circledR}$ aerosol was $17 \mathrm{~m} \cdot \mathrm{s}^{-1}$, decelerating to $7 \mathrm{~m} \cdot \mathrm{s}^{-1}$ after $10 \mathrm{~ms}$. After 
Table 1. - The amount of salbutamol ( $\mu \mathrm{g}$ per $100 \mu \mathrm{g}$ dose) recovered in particles smaller than 5 and $3 \mu \mathrm{m}$ aerodynamic diameter, the MMAD and GSD of the aerosol from different spacer devices

\begin{tabular}{|c|c|c|c|c|}
\hline \multirow[t]{2}{*}{ Method of delivery } & \multicolumn{4}{|c|}{ Amount of salbutamol recovered $(\mu \mathrm{g})$ per $100 \mu \mathrm{g}$ actuation } \\
\hline & $\begin{array}{l}\text { In particles } \\
<5 \mu \mathrm{m}\end{array}$ & $\begin{array}{c}\text { In particles } \\
<3 \mu \mathrm{m}\end{array}$ & $\begin{array}{l}\text { MMAD } \\
\mu \mathrm{m}\end{array}$ & GSD \\
\hline \multicolumn{5}{|c|}{ Direct from metered-dose inhalers } \\
\hline Airomir ${ }^{\circledR}$ & $37.2(35.5-38.8)$ & $28.5(27.1-29.9)$ & $5.7(5.6-5.9)$ & $4.9(4.7-5.2)$ \\
\hline Ventolin ${ }^{\circledR}$ & $46.3(36.3-56.3)$ & $34.4(27.5-41.3)$ & $5.2(3.9-6.5)$ & $4.8(3.2-6.4)$ \\
\hline \multicolumn{5}{|c|}{ Via the Aerochamber ${ }^{\circledR}$} \\
\hline Airomir ${ }^{\circledR}$ & $40.4(31.2-49.6)$ & $33.6(26.1-41.1)$ & $1.8(1.7-1.9)$ & $2.5(2.4-2.7)$ \\
\hline Ventolin ${ }^{\circledR}$ & $19.5(18.9-20.0)$ & $15.9(15.4-16.5)$ & $1.9(1.8-2.1)$ & $2.9(2.6-3.1)$ \\
\hline \multicolumn{5}{|l|}{ Via the Nebuhaler ${ }^{\circledR}$} \\
\hline Airomir $\AA$ & $42.1(36.3-47.9)$ & $35.4(30.6-40.3)$ & $1.6(1.5-1.8)$ & $2.5(2.4-2.6)$ \\
\hline Ventolin ${ }^{\circledR}$ & $24.6(23.3-25.8)$ & $20.5(19.4-21.6)$ & $1.7(1.6-1.8)$ & $2.6(2.4-2.8)$ \\
\hline \multicolumn{5}{|c|}{ Via the Antistatic Nebuhaler ${ }^{\circledR}$} \\
\hline Airomir ${ }^{\circledR}$ & $74.8(64.0-85.6)$ & $63.1(52.8-73.5)$ & $1.6(1.5-1.8)$ & $2.3(2.3-2.4)$ \\
\hline Ventolin $®$ & $68.5(61.2-75.7)$ & $56.8(50.2-63.4)$ & $1.8(1.7-1.8)$ & $2.6(2.4-2.7)$ \\
\hline
\end{tabular}

Mean values are presented, and 95\% confidence intervals in parentheses. MMAD: mass median aerodynamic diameter; GSD: geometric standard deviation.

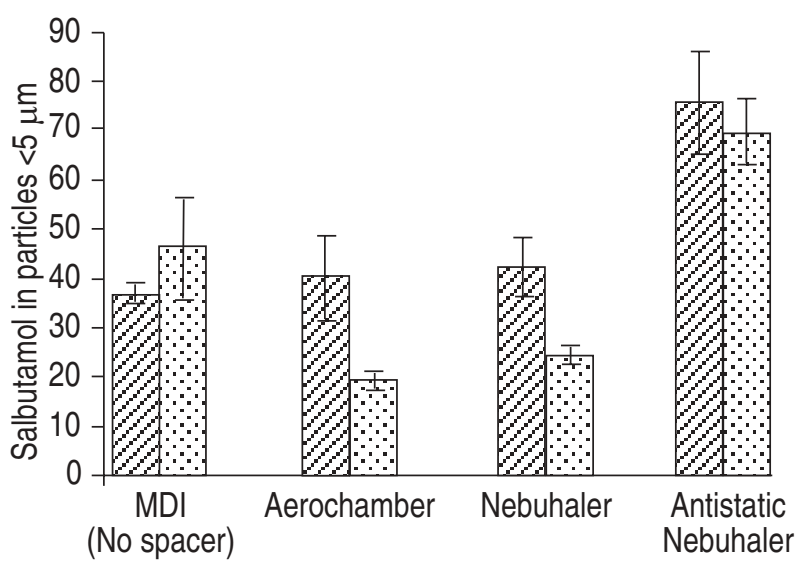

Fig. 1. - The amount of salbutamol ( $\mu \mathrm{g}$ per $100 \mu \mathrm{g}$ dose $)$ recovered in particles smaller than $5 \mu \mathrm{m}$ aerodynamic diameter from the different spacer devices. $\square$ : Airomir®; $\square$ : Ventolin®. The error bars represent $95 \%$ confidence intervals. MDI: metered-dose inhaler.

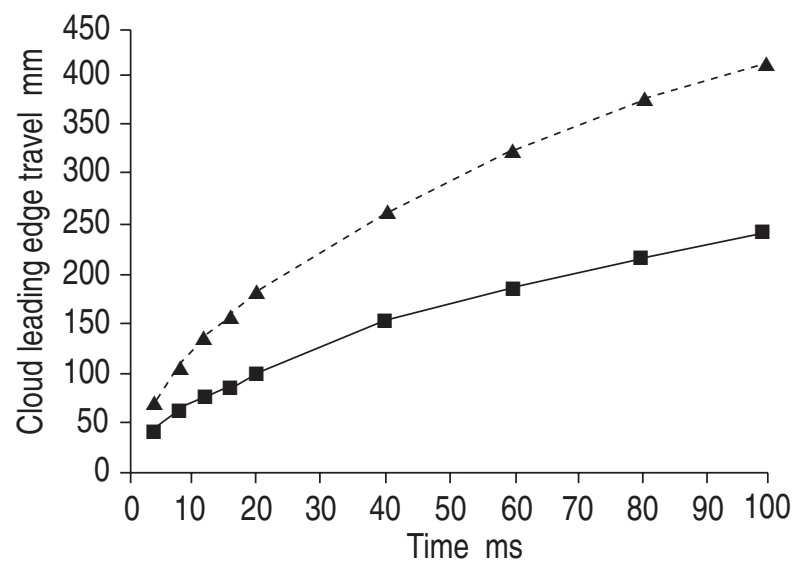

Fig. 2. - The distance travelled by the leading edge of the aerosol cloud $(\mathrm{mm})$ against time after metered-dose inhaler (MDI) actuation (ms) for Airomir ${ }^{\circledR}(-\mathbf{-}-)$ and Ventolin ${ }^{\circledR}(-\boldsymbol{\Delta}-)$ MDIs.

$60 \mathrm{~ms}$, the Airomir® aerosol had travelled $186 \mathrm{~mm}$, and was moving at $1.6 \mathrm{~m} \cdot \mathrm{s}^{-1}$; the Ventolin ${ }^{\circledR}$ aerosol had travelled $320 \mathrm{~mm}$, and was moving at $3.1 \mathrm{~m} \cdot \mathrm{s}^{-1}(\mathrm{p}<0.0001)$. At the same time, the Airomir ${ }^{\circledR}$ aerosol volume was 251 $\mathrm{cm}^{3}\left(95 \%\right.$ CI $\left.213-288 \mathrm{~cm}^{3}\right)$, and the Ventolin ${ }^{\circledR}$ aerosol volume was $695 \mathrm{~cm}^{3}\left(608-782 \mathrm{~cm}^{3}\right)(\mathrm{p}<0.0001)$.

\section{Discussion}

This study shows large differences in the amount of drug obtained in small particles when the conventional and CFC-free formulations of salbutamol MDIs are used with different spacer devices, and in the aerosol cloud geometry and speed of the two different formulations.

Spacer devices are becoming increasingly popular for the delivery of inhaled drugs in the treatment of asthma [11]. They act as "holding chambers" for aerosol, reducing the need for the patient to co-ordinate inhalation with MDI actuation. They also provide space between the patient and the MDI allowing the fast-moving aerosol to decelerate, and propellants to evaporate, reducing aerosol particle size. This reduces the amount of drug that impacts on the oropharynx and enhances lung deposition of drug [12]. Popularity has led to a rapid increase in the number of different types of spacer available and, by the attachment of face masks, they can be adapted to treat patients of all ages [13].

Despite their seemingly simple construction and concept, however, the correct choice and use of a spacer can dramatically alter the amount of drug available for inhalation. Recent in vitro studies have suggested that the behaviour of different drugs may vary in a particular type of spacer [3], as may different formulations of the same drug [14].

Drug particles are deposited in spacers by inertial impaction, electrostatic attraction between charged particles and the spacer wall, and gravitational settling. The aerosol produced by the Ventolin ${ }^{\circledR}$ MDI was moving faster than that produced by the Airomir ${ }^{\circledR}$ MDI. Others have also measured the speed of aerosols from MDIs [15], producing results similar to those of the present study for a Ventolin ${ }^{\circledR}$ MDI. Particles from the Ventolin ${ }^{\circledR}$ MDI would have reached the end of the Aerochamber ${ }^{\circledR}$ (11 cm length) some $8 \mathrm{~ms}$ after MDI actuation, compared with 23 ms for Airomir®. Thus, when they reached the end of the spacer, the particles from the Ventolin ${ }^{\circledR}$ MDI would have been travelling faster, and would have been bigger, as less time had elapsed for evaporation of propellants surrounding the drug. Increased inertial impaction of the Ventolin ${ }^{\circledR}$ aerosol on the spacer wall may occur and be a reason for the difference in drug output observed. The Ventolin ${ }^{\circledR}$ aerosol also occupied a 
larger volume than the Airomir ${ }^{\circledR}$, and at $60 \mathrm{~ms}$ after MDI actuation would have completely filled the Nebuhaler ${ }^{\circledR}$ (700 mL volume), whereas the Airomir ${ }^{\circledR}$ would have occupied just over a third of the spacer volume. Drug particles from the Ventolin ${ }^{\circledR}$ aerosol would, therefore, have been closer to the spacer walls at any given time after MDI actuation. Mechanisms, such as electrostatic attraction, diffusion and interception, which promote aerosol deposition are all greater for particles close to the spacer walls.

The antistatic spacer increased the recovery both from Airomir ${ }^{\circledR}$ and Ventolin® MDI. We did not measure the static charge of the aerosol particles, but differences in either the charge or the static dissipative properties of the aerosol constituents may also have contributed to the observed differences in drug delivery.

Our work confirms the principle that the efficacy of a particular spacer with one formulation cannot be assumed for another formulation, even of the same drug. Thus, it is inappropriate to use any drug with any device uncritically just because the MDI adapter fits [3].

The Nebuhaler $\AA$ is not recommended for use either with Ventolin ${ }^{\circledR}$ or Airomir ${ }^{\circledR}$ MDIs. Ventolin ${ }^{\circledR}$ is normally prescribed with the Volumatic ${ }^{\circledR}$ spacer, but the Airomir ${ }^{\circledR}$ MDI actuator does not fit the Volumatic $\AA$, and the Nebuhaler ${ }^{\circledR}$ was, therefore, assessed as an example of a large volume spacer. It may be that the poor fit of the Ventolin ${ }^{\circledR}$ MDI adapter affected our results. However, we have previously undertaken a similar study with Ventolin ${ }^{\circledR}$ used with the Volumatic ${ }^{\circledR}$ spacer [16], in which $24.6 \mu \mathrm{g}$ of salbutamol was recovered in particles smaller than $5 \mu \mathrm{m}$, a similar amount to that obtained from the Nebuhaler® in the present study. We have also published data on recovery from Volumatic ${ }^{\circledR}$ spacers that had been washed to reduce their static charge [8], obtaining similar recoveries of salbutamol to the present study from the low static Nebuhaler ${ }^{\circledR}(54.3 v s 68.5 \mu \mathrm{g}$ in particles smaller than $5 \mu \mathrm{m}$ ).

The MSLI is a particle-sizing device that does not mimic respiration or act as a model lung, and particle size is only one of a number of factors that determines the fate of inhaled medication. However, recent pharmacokinetic studies [17] have supported in vitro studies of spacer use, suggesting that laboratory studies, such as this, provide useful information with which to evaluate different drug delivery systems. Comparative clinical studies of patients with asthma comparing the CFC and HFA formulations administered via spacers have not, to our knowledge, been undertaken, and the clinical relevance of small differences in bronchodilator delivery with different spacers is not clear. However, this may be important where the dose delivered needs to be high (as in the treatment of an exacerbation of asthma) and precisely known, for instance in comparative studies of the effects of different drugs.
Acknowledgements: The authors thank 3M Health Care for supplying the Airomir®, and Static Safe Ltd, Birmingham, UK, for supplying the antistatic coating for the Nebuhaler®.

\section{References}

1. Partridge MR. Metered-dose inhalers and CFCs: what respiratory physicians need to know. Respir Med 1994; 88: 645-647.

2. Levison H. Reilly PA, Worsley GH. Spacing devices and metered-dose inhalers in childhood asthma. $J$ Pediatr 1985; 107: 662-668.

3. Barry PW, O'Callaghan C. Inhalational drug delivery from seven different spacer devices. Thorax 1996; 51: $835-840$.

4. O'Callaghan C, Lynch J, Cant M, Robertson C. Improvement in drug delivery from spacer devices by use of an antistatic lining. Thorax 1993; 48: 603-606.

5. Barry PW, O'Callaghan C. Video analysis of the aerosol cloud produced by metered-dose inhalers. Pharm Sci 1995; 1: 119-121.

6. May KR. Multistage liquid impinger. Bacter Rev 1966; 30: 559-570.

7. Bell JH, Brown K, Glasby J. Variations in the delivery of isoprenaline from various pressurised inhalers. $J$ Pharm Pharmacol 1973; 25 (Suppl.): 32-36.

8. Barry PW, O'Callaghan C. Multiple actuations of salbutamol metered-dose inhaler into a spacer device reduce the amount of drug recovered in the respirable range. Eur Respir J 1994; 7: 1707-1709.

9. Hinds WC. Aerosol Technology. New York, John Wiley \& Sons, 1983.

10. Matthews JNS, Altman DG, Campbell MJ, Royston P. Analysis of serial measurements in medical research. BMJ 1990; 300: 230-235.

11. Keeley D. Large volume plastic spacers in asthma (Editorial). BMJ 1992; 305: 598-599.

12. Newman SP. Improvement of pressurised aerosol deposition with the Nebuhaler spacer device. Thorax 1984; 39: 935-941.

13. O'Callaghan C, Milner AD, Swarbrick A. Spacer device with face-mask attachment for giving bronchodilators to infants with asthma. BMJ 1989; 298: 160-161.

14. Miller MR, Bright P. Differences in output from corticosteroid inhalers used with a Volumatic spacer. Eur Respir J 1995; 8: 1637-1638.

15. Dhand R, Malik SK, Balakrishnan M, Verma SR. High speed photographic analysis of aerosols produced by metered-dose inhalers. J Pharm Pharmacol 1988; 40: 429-430.

16. Barry PW, O'Callaghan C. Poor output of salbutamol from a spacer device: effect of spacer static charge and multiple actuations (Abstract). Thorax 1994; 49: 402P.

17. Clarke DJ, Lipworth BJ. Lung bioavailability of salbutamol from a spacer device comparing single versus multiple actuations, delayed inhalation and antistatic treated spacer (Abstract). Thorax 1995; 50 (Suppl. 2): A79. 